\title{
Proteomics analysis of Schwann cell-derived exosomes: a novel therapeutic strategy for central nervous system injury
}

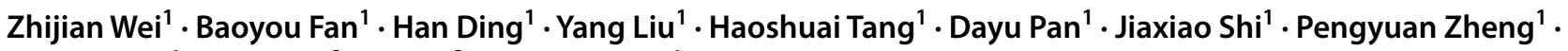 \\ Hongyu Shi ${ }^{1} \cdot$ Heng $\mathrm{Wu}^{2} \cdot{\text { Ang } \mathrm{Li}^{3} \text {. Shiqing Feng }}^{1}$
}

Received: 21 October 2018 / Accepted: 14 February 2019 / Published online: 4 March 2019

(c) The Author(s) 2019

\begin{abstract}
Exosomes are nanometer-sized vesicles involved in intercellular communication, and they are released by various cell types. To learn about exosomes produced by Schwann cells (SCs) and to explore their potential function in repairing the central nervous system (CNS), we isolated exosomes from supernatants of SCs by ultracentrifugation, characterized them by electron microscopy and immunoblotting and determined their protein profile using proteomic analysis. The results demonstrated that Schwann cell-derived exosomes (SCDEs) were, on average, $106.5 \mathrm{~nm}$ in diameter, round, and had cup-like concavity and expressed exosome markers CD9 and Alix but not tumor susceptibility gene (TSG) 101. We identified a total of 433 proteins, among which 398 proteins overlapped with the ExoCarta database. According to their specific functions, we identified 12 proteins that are closely related to CNS repair and classified them by different potential mechanisms, such as axon regeneration and inflammation inhibition. Gene Oncology analysis indicated that SCDEs are mainly involved in signal transduction and cell communication. Biological pathway analysis showed that pathways are mostly involved in exosome biogenesis, formation, uptake and axon regeneration. Among the pathways, the neurotrophin, PI3K-Akt and cAMP signaling pathways played important roles in CNS repair. Our study isolated SCDEs, unveiled their contents, presented potential neurorestorative proteins and pathways and provided a rich proteomics data resource that will be valuable for future studies of the functions of individual proteins in neurodegenerative diseases.
\end{abstract}

Keywords Schwann cell $\cdot$ Exosomes $\cdot$ Central nervous system $\cdot$ Proteomics

Zhijian Wei, Baoyou Fan, and Han Ding have contributed equally to this work.

Electronic supplementary material The online version of this article (https://doi.org/10.1007/s11010-019-03511-0) contains supplementary material, which is available to authorized users.

Shiqing Feng

sqfeng@tmu.edu.cn

1 Department of Orthopedics, Tianjin Medical University General Hospital, Tianjin 300052, China

2 Tianjin Key Laboratory of Lung Cancer Metastasis and Tumor Microenvironment, Tianjin Lung Cancer Institute, Tianjin Medical University General Hospital, Tianjin 300052, China

3 Department of Orthopedics, Henan Provincial People's Hospital, Zhengzhou 450000, China

\section{Introduction}

Central nervous system (CNS) injury, such as spinal cord injury and brain injury, causes irreversible loss of motor and sensory function $[1,2]$. Due to the development of modern society, the occurrence rate of CNS damage increases year by year. The predicament of CNS regeneration is always attributed to the poor regenerative plasticity of mature neurons as well as the detrimental microenvironment caused by the lesion [3]. The peripheral nervous system (PNS) exhibits adequate regeneration after injury, which is different from the CNS. During this process, glial cells in situ play a more important role than functional neurons. In the CNS, multiple growth inhibitory factors derived from oligodendrocytes, such as Nogo, myelin-associated glycoprotein (MAG), and oligodendrocyte myelin glycoprotein (OMgp), induce the collapse of the growth cone [4]. Conversely, in the PNS, Schwann cells promote nerve regeneration through secreting 
growth factors, clearing myelin and axonal debris, activating macrophages and forming new medullary sheath [5].

Taking the advantages of Schwann cells into consideration, many studies have attempted to transplant these cells into injured CNS. This strategy obtained many encouraging results [6]. The advantages of Schwann cell transplantation include the practicability of autologous transplantation [7, 8] and synergistic effects combined with other strategies $[9,10]$. However, some evidence still causes researchers to believe that Schwann cells transplanted into the CNS cannot perform as ideally as they can in the PNS. A major challenge for Schwann cell CNS transplantation is the low graft cell survival due to p75NTR-induced apoptosis $[11,12]$ and limited migration ability across the astrocyte boundary [13, 14]. Therefore, whether a previous favorable improvement is the mutual factor between active and adverse effects after $\mathrm{SC}$ transplantation in the CNS remains to be determined. We hypothesized that there should be a new strategy to optimize the ability of SCs to minimize undesirable characteristics.

Exosomes are small vesicles with a diameter of approximately $50-100 \mathrm{~nm}$ that are produced in the endosomal compartment and filled with functional proteins, microRNAs (miRNAs) and mRNAs [15]. They are involved in intercellular communication and are secreted continuously under many physiological and pathological conditions [16]. Their subparticle nature in the host cells makes them serve as microenvironment modulators through paracrine mechanisms to ease stimuli [17]. A recent study demonstrated that exosomes derived from Schwann cells support axonal maintenance and regeneration after PNS damage [18]. Considering the positive performance of SCs in CNS repair, we wondered whether the use of their exosomes is the optimal strategy to replace cell transplantation. Because of the complexity CNS composition, understanding exosome content is necessary to explore potential target cells. Until now, only individual proteins have been identified by various studies [19], which leads to the requirement of comprehensive information about the proteins in Schwann cell-derived exosomes (SCDEs).

In the current study, we purified exosomes from SC-conditioned medium and explored their morphological features and biomarkers. Furthermore, 433 proteins were identified from SCDEs using LC-MS/MS. Systematic proteomics characteristics were obtained through bioinformatics analysis. This study provides new evidence that SCDEs may act as a novel therapeutic strategy for CNS injury.

\section{Methods}

\section{Isolation of exosome vesicles by ultracentrifugation}

Primary SCs derived from the sciatic nerve of adult Wistar rats (female, $230 \mathrm{~g} \pm 10 \mathrm{~g}$, provided by the Academy of Military Medical Sciences, Tianjin, China) were cultured, and exosome isolation was performed as described previously with minor modifications in Fig. 1 [9, 18]. All animal procedures were approved by the Ethics Committee of Tianjin Medical University and were in accordance with the Guidance Suggestions for the Care and Use of Laboratory Animals. First, the SCs were cultured in exosome-depleted growth medium, and the cell conditioned medium was collected. Then, dead cells and large growth debris were removed through centrifugation $(1000 \times g, 20 \mathrm{~min})$. Second,
Fig. 1 Isolation procedure of Schwann cell-derived exosomes and the workflow of proteomic analysis. a The isolation procedure of Schwann cell-derived exosomes (SCDEs) and $\mathbf{b}$ workflow for the processing of SCDEs for a comprehensive proteomic analysis
A

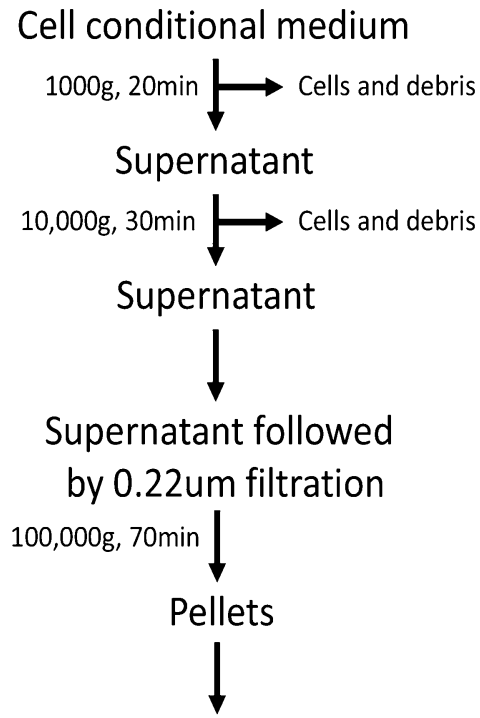

Exosome re-suspend with cold PBS
B

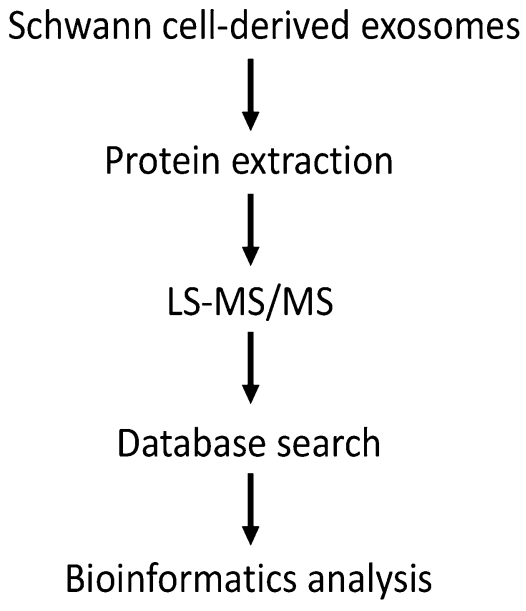


to remove additional debris, the supernatant was centrifuged at $10,000 \times g$ for $30 \mathrm{~min}$. Then, the supernatant was filtered using $0.22-\mu \mathrm{m}$ filters (Millipore, CA). Then, the filtered supernatant was centrifuged at $100,000 \times g$ for $70 \mathrm{~min}$ to collect the exosomes. Finally, the exosomes were resuspended in cold PBS for further experiments.

\section{Characterization of SCDEs by transmission electron microscopy (TEM) and the Malvern Zetasizer Nano ZS90}

Transmission electron microscopy (TEM) was used for morphological observation. The exosome samples were prepared as described above. For TEM, briefly, the exosomes were fixed with $2.5 \%$ glutaraldehyde overnight at $4{ }^{\circ} \mathrm{C}$. The solution was centrifuged at $100,000 \times g$ to remove the glutaraldehyde, and the exosomes were washed three times with PBS. Then, the exosomes were stained with $3 \%$ phosphotungstic acid aqueous solution and fixed on copper mesh formvar grids. A transmission electron microscope (JEM-1010) was used to detect the exosomes. A Malvern Zetasizer Nano ZS90 (Malvern, UK) was used to detect the concentration of exosomes in different samples. Samples with appropriate concentrations were used to examine the size distribution of exosomes.

\section{Western blot}

Exosome samples were lysed with RIPA buffer, and the collected protein samples were added to $5 \times$ SDS loading buffer and denatured by boiling for $5 \mathrm{~min}$. Then, $10 \%$ acrylamide gels were used for electrophoresis, and the proteins were transferred to PVDF membranes for $2 \mathrm{~h}$. After washing three times with TBST, the membranes were blocked with blocking buffer (5\% nonfat milk in PBS) for $1 \mathrm{~h}$ at room temperature (RT). Then, the membranes were incubated with primary antibodies overnight at $4{ }^{\circ} \mathrm{C}$. The antibodies were diluted as follows: CD9 (rabbit monoclonal 1:2000; Abcam), Alix (mouse monoclonal 1:1000; Cell Signaling Technology) and TSG101 (rabbit monoclonal 1:500; Abcam). The next day, the membranes were washed three times with TBST and incubated with secondary antibody (1:2000) for $1 \mathrm{~h}$ at RT. Blots were detected using enhanced chemiluminescence.

\section{Protein digestion}

Briefly, the obtained exosomes were lysed by 4\% SDS, $100 \mathrm{mM}$ DTT, and $50 \mathrm{mM}$ Tris, and $\mathrm{HCl}$ (pH 7.5). According to the FASP protocol, trypsin was used to digest total proteins $(20 \mu \mathrm{g})$. The proteins were denatured for $5 \mathrm{~min}$ at $95^{\circ} \mathrm{C}$ and mixed with $200 \mathrm{~mL}$ UA buffer solution $(8 \mathrm{M}$ urea in $0.1 \mathrm{M}$ Tris $\mathrm{HCl} \mathrm{pH} 8.5)$ and centrifuged $(12,000 \mathrm{rpm})$ three times for $15 \mathrm{~min}$. Next, the samples and $100 \mathrm{~mL}$ of iodoacetamide (IAA) were mixed at $600 \mathrm{rpm}$ in a hot mixer. The filter unit was incubated for $20 \mathrm{~min}$ and centrifuged for $10 \mathrm{~min}$ at $12,000 \mathrm{rpm}$. One hundred milliliters of UA was added to the filter unit and centrifuged at 12,000 rpm three times for $15 \mathrm{~min}$. Then, $100 \mathrm{~mL}$ of $50 \mathrm{mM} \mathrm{NH} \mathrm{HCO}_{3}$ was added to the filter unit and centrifuged at 12,000 rpm three times for $15 \mathrm{~min}$. Then, the samples were mixed with trypsin (with $50 \mathrm{mM} \mathrm{NH}_{4} \mathrm{HCO}_{3}$ ) and placed in the thermal mixer at $600 \mathrm{rpm}$. Then, these units were incubated in a wet chamber at $37^{\circ} \mathrm{C}$ overnight. The filtration unit was transferred into the new collecting pipe and centrifuged for $15 \mathrm{~min}$ at $12,000 \mathrm{rpm}$. Then, $50 \mathrm{mM} \mathrm{NH}_{4} \mathrm{HCO}_{3}$ was added to the filter unit and centrifuged for $15 \mathrm{~min}$ at $12,000 \mathrm{rpm}$. Then, the samples were dried and stored at $-20{ }^{\circ} \mathrm{C}$ until LC-MS/MS.

\section{LC-MS/MS}

Referring to a previous study [20], LC-MS/MS was performed with some modifications. In short, the final concentration of the samples was $0.1 \%(\mathrm{~V} / \mathrm{V})$ after dilution with formic acid. The samples were then loaded onto a $75 \mathrm{~mm} \mathrm{x}$ $150 \mathrm{~mm}$ fused silica column that was packed in-house with 3-mm ReproSil-Pur C18 beads (120 ̊ं; Dr. Maisch GmbH, Ammerbuch, Germany). LC-MS/MS was performed using an Easy Nano-UPLC 1000 (Thermo Electron, Waltham, MA). A gradient (5-80\% acetonitrile and $0.1 \%$ formic acid) was used to elute peptides on the Q-Exactive mass spectrometer (Thermo Electron, Waltham, MA) in the flow rate of 300 1/min over $240 \mathrm{~min}$. The MS/MS spectrum was obtained in the data-dependent mode, and the scan resolution was 70,000 during acquisition (m/z 200).

\section{Data processing}

Raw data files were processed with Proteome Discoverer (v1.3; Thermo Scientific).

Then, Mascot 2.3.02 (Matrix Science) Boston, MA, software was used to search against the Bovine RefSeq database. Two missed cleavages are allowed for tryptic enzymes. Carbamidomethylation (C) was set to fixed modification, and oxidation (M) and acetylation (N-term) were set as variable modifications. The peptide difference was $20 \mathrm{ppm}$, the fragment ion mass error was $0.1 \mathrm{Da}$, and the peptide and protein identification error rates were $<1 \%$.

\section{Gene Ontology annotation and pathway analysis}

Functional-enrichment analysis for Gene Ontology (GO) terms was conducted through the Database for Annotation, Visualization and Integrated Discovery (DAVID, v6.8) (https://david.ncifcrf.gov/) with the entire murine genome as the background. The enriched GO analysis of annotated 
proteins was performed for cellular components, molecular functions and biological processes. Pathways enriched with the proteins were generated by KEGG pathway analysis and Cytoscape software 3.5.1. The Venn diagrams web tool (http://bioinformatics.psb.ugent.be/webtools/Venn/) was used to compare the proteins identified with the ExoCarta database. GraphPad Prism 6.0 was used for plotting.

\section{Results}

\section{Characterizations of Schwann cell-derived exosomes}

To explore the neuroprotective effect of SCDEs, we isolated exosomes from cultured Schwann cells. Schwann cells were positive for $\mathrm{S} 100$ (Fig. 2a). After observation using the Malvern Zetasizer Nano ZS90, the mean diameter of the SCDEs was $106.5 \mathrm{~nm}$ (Fig. 2b). We performed Western blotting to detect CD9, Alix and TSG101 expression to characterize these exosomes. The results showed that CD9 and Alix, which are exosome markers, could be detected, but TSG101 was not (Fig. 2c), which is consistent with exosome characteristics [18]. In addition, the morphology of SC-released exosomes was further confirmed through TEM, which showed SCDEs with a size range of 40-100 nm (Fig. 2d).

\section{Proteomic analysis of Schwann cell-derived exosomes}

We repeated the experiments three times (Supplementary Figure). To reveal the mechanisms of the neuroprotective effect of SCDEs, we performed proteomic analysis on
SCDEs. Finally, 433 proteins in exosomes that were concordant in the three biological duplicates were identified and compared with the exosome database, ExoCarta; 398 proteins overlapped (Fig. 3) and were ranked based on intensity values (Supplementary Table). Thus, $91.92 \%$ of the identified proteins overlapped with ExoCarta, which indicated that the procedures for isolation and purification are repeatable, and the results of proteomic analysis are reliable. As shown in Table 1, most of the identified proteins are related to CNS repair.

\section{SCDEs might enhance axon regeneration}

Several studies have reported that SCDEs play a critical role in axonal regeneration in the PNS [18, 44, 45]. However, whether SCDEs enhance axon regeneration in the CNS is

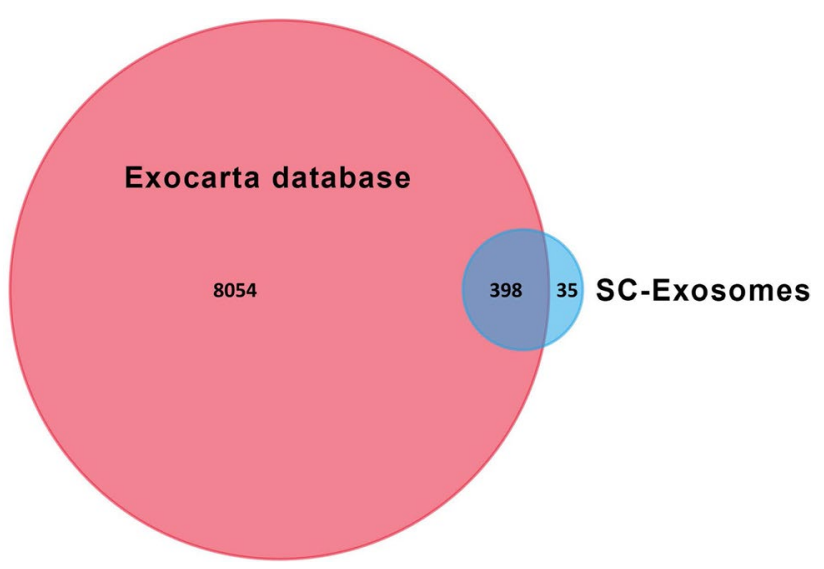

Fig. 3 Venn diagrams of SCDEPs against the database of ExoCarta
Fig. 2 Characterizations of Schwann cell-derived exosomes. Characterization of the isolated SCDEs. a Schwann cells were positive for $\mathrm{S} 100$. $(\mathrm{Bar}=50 \mu \mathrm{m})$. b The size distribution of SCDEs was detected by the Malvern Zetasizer Nano ZS90. c The expression of CD9, Alix, and TSG101 was detected by Western blot in the Schwann cell lysate (SCL) group and Schwann cell-derived exosome (SCDE) group. d TEM image of SCDEs
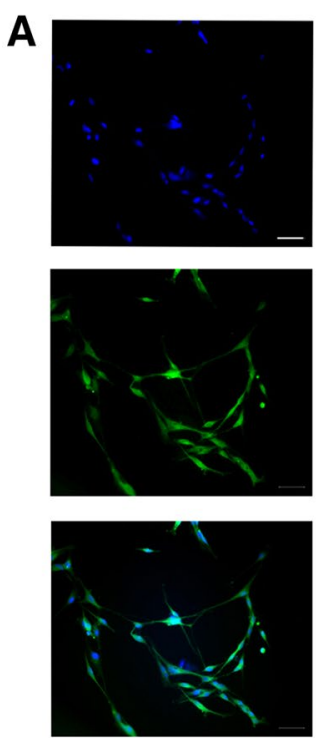

B

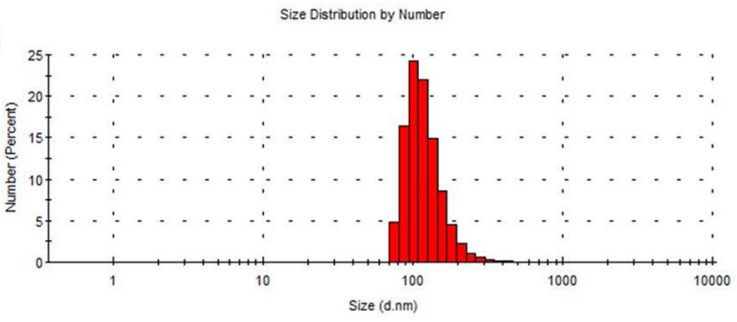

C

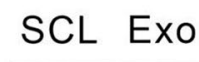

CD9

Alix

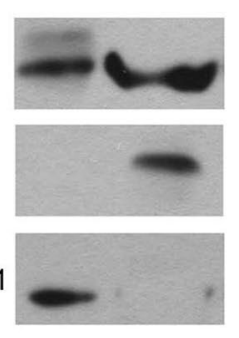

D

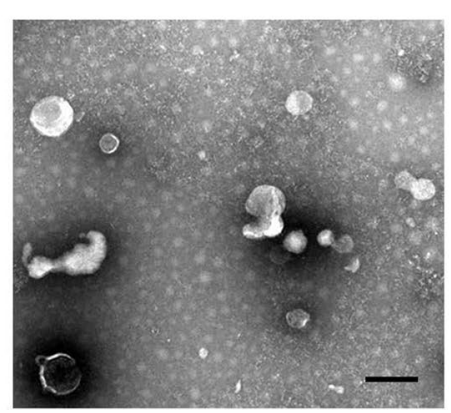


Table 1 Exosome proteins associated with repair of SCI

\begin{tabular}{llll}
\hline Protein name & Protein IDs & Gene names & Role in repair of SCI \\
\hline Carboxypeptidase E & P15087 & CPE & Axon regeneration [21, 22] \\
Fatty acid-binding protein & P55053 & FABP5 & Axon regeneration [23, 24] \\
Fibronectin & P04937 & FN1 & Axon regeneration [25, 26] \\
Flotillin-2 & Q9Z2S9 & FLOT2 & Axon regeneration [27-29] \\
Major vault protein & Q62667 & MVP & Axon regeneration [30] \\
Monocarboxylate transporter 1 & P53987 & SLC16A1 & Axon regeneration [31, 32] \\
Neuropilin-2 & O35276 & NRP2 & Axon regeneration [33, 34] \\
Septin-7 & Q9WVC0 & SEPT7 & Axon regeneration [35, 36] \\
Protein disulfide-isomerase A3 & P11598 & PDIA3 & Axon regeneration [37-39] \\
Syntenin-1 & Q9JI92 & SDCBP & Axon regeneration [40] \\
$\alpha B-C r y s t a l l i n$ & P23928 & CRYAB & Inhibit inflammation [41] \\
Galectin-1 & P11762 & LGALS1 & Inhibit inflammation [42, 43] \\
\hline
\end{tabular}

still unclear. According to the proteomics results, twelve proteins were closely related to axon regeneration, such as carboxypeptidase $\mathrm{E}$ (CPE), fatty acid-binding protein (FABP5), fibronectin, flotillin-2, major vault protein (MVP), monocarboxylate transporter 1 (MCT1), neuropilin-2 (NRP2), septin-7 (SEPT7), protein disulfide-isomerase A3 (PDIA3) and syntenin-1. As SCDEs contain proteins involved in axon regeneration, this result reveals that the function of SCs in promoting axonal regeneration might be through exosomes.

\section{SCDEs might inhibit inflammation}

Exosomes from several kinds of cells participate in the inhibition of the inflammatory response, which is considered a novel therapeutic approach for some diseases [46-48]. Likewise, two proteins that we found in SCDEs, $\alpha \mathrm{B}$-crystallin and galectin-1, might produce benefits similar to anti-inflammatory effects in CNS injury. Thus, SCDEs might have an anti-inflammatory role in CNS damage.

\section{Functional categories}

Next, GO annotation was performed to determine the functional roles of the SCDE proteins (SCDEP) via DAVID version 6.8 and to obtain the enriched terms for molecular function, biological process and cellular component. The GO classification system revealed that the proteins could be classified into groups according to their functional properties (Fig. 4a-c). The biological processes analysis revealed enrichment of SCDEP related to "cell adhesion", "negative regulation of apoptotic" and "signal transduction". For the cellular component, these proteins were enriched in "exosomes", the "cytoplasm" and the "membrane". The molecular functions of the exosome proteins are mainly enriched in "protein binding", "poly (A) RNA binding" and "GTP binding".

\section{KEGG pathway analysis}

The enriched signaling pathways with the exosome proteins were determined using KEGG pathway analysis. The top 20 pathways based on enrichment were given. As shown in Table 2, the top 20 pathways enriched with a p value $<0.05$ were focal adhesion, endocytosis, regulation of the actin cytoskeleton and the PI3K-Akt signaling pathway. Among these, the neurotrophin signaling pathway, PI3K-Akt signaling pathway and cAMP signaling pathway are related to the CNS microenvironment.

\section{Discussion}

Schwann cells are the main functional glial cells in the PNS and play a very important role in axon regeneration after PNS injury. Recent studies believe that Schwann cells and their encapsulated axons should be deemed a "functional syncytium" [44] because of the inadequate capability of overlong axons to transport enough proteins in time and the evidence of substance exchange between axons and Schwann cells. Exosomes are small vesicles carrying functional molecules from host cells and play an important role in cell-cell communication [49]. Exosomes derived from Schwann cells modulate the damaged PNS microenvironment and enhance axonal regeneration by inhibiting the activity of the GTPase RhoA [18]. This finding gives us a new promising strategy for other neurodegenerative disorders, such as amyotrophic lateral sclerosis (ALS), Alzheimer's disease (AD) and brain and spinal cord injury. Therefore, there is an urgent need to investigate exosome contents, which can help us gain a deeper understanding of potential therapeutic mechanisms. In this study, we isolated SCDEs and verified the size, morphology and surface markers associated with exosome characteristics. Then, proteomics analysis was performed, and 433 proteins were identified through LC-MS/ 
A

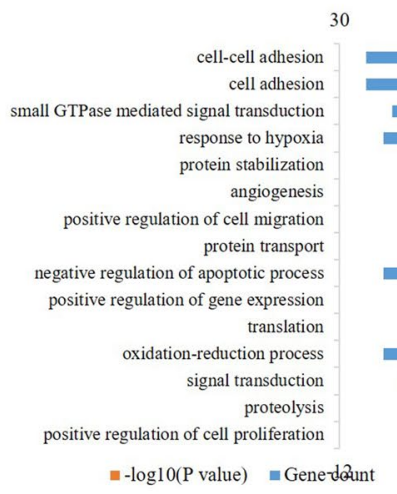

Biological Process

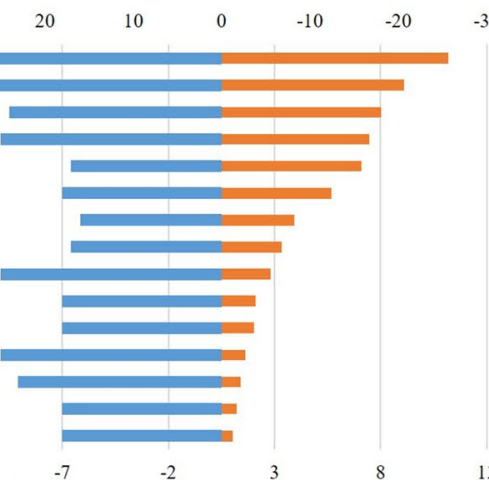

B cell-cell. threonine-type endopeptidase activity protein kinase binding protein kinase binding poly(A) RNA binding
domain specific binding unfolded protein binding structural constituent of cytoskeleton enzyme binding GDP binding GDP binding
protein complex binding MHC class II protein complex binding protein homodimerization activity
ubiquitin protein ligase binding =-LOG10(P value) $=$ Gene count -35
Molecular Function

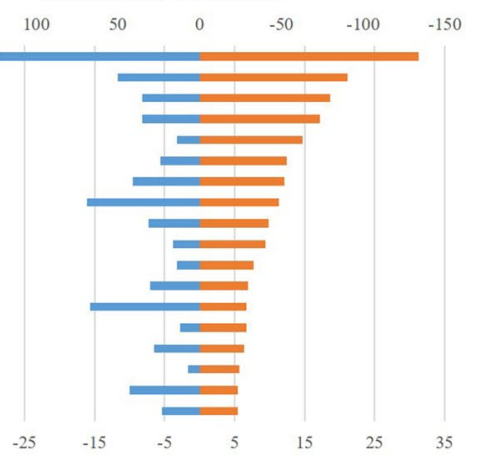

C

Celluar Compotent

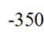

extracellular exosom

focal adhesion

myelin sheath

membrane
cytoplasm

extracellular matrix

extracellular space cytosol

cell-cell adherens junction perinuclear region of cytoplasm

proteasome core complex

membrane raft
vesicle

stress fibe

cell surface

$350 \quad 250$

$150 \quad 50 \quad-50 \quad-150 \quad-250 \quad-350$

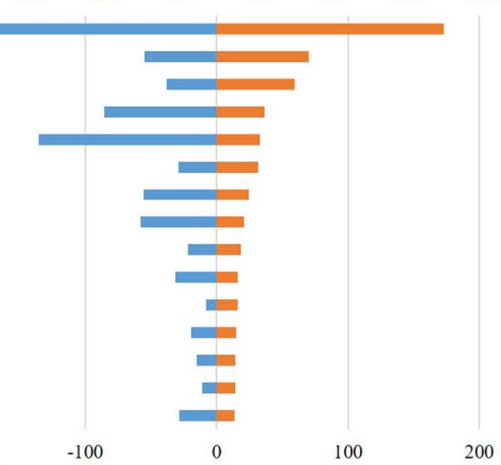

$=-200$

$-100$

0

200

Fig. 4 Gene Ontology (GO) analysis of biological processes, cellular components and molecular functions

Table 2 KEGG pathway analysis

\begin{tabular}{llll}
\hline Number & Term & Count & $P$ Value \\
\hline 1 & rno04510: Focal adhesion & 26 & $2.13 \mathrm{E}-07$ \\
2 & rno04144: Endocytosis & 26 & $5.92 \mathrm{E}-05$ \\
3 & rno04810: Regulation of actin cytoskeleton & 24 & $5.46 \mathrm{E}-06$ \\
4 & rno04151: PI3K-Akt signaling pathway & 21 & 0.0269219 \\
5 & rno03010: Ribosome & 20 & $1.91 \mathrm{E}-05$ \\
6 & rno04145: Phagosome & 19 & $3.44 \mathrm{E}-04$ \\
7 & rno04015: Rap1 signaling pathway & 18 & 0.002744107 \\
8 & rno04024: cAMP signaling pathway & 15 & 0.013664262 \\
9 & rno04921: Oxytocin signaling pathway & 12 & 0.035715206 \\
10 & rno04141: Protein processing in endoplasmic reticulum & 12 & 0.048063015 \\
11 & rno04062: Chemokine signaling pathway & 12 & 0.065106331 \\
12 & rno00480: Glutathione metabolism & 11 & $4.59 \mathrm{E}-05$ \\
13 & rno04915: Estrogen signaling pathway & 11 & 0.002866544 \\
14 & rno04270: Vascular smooth muscle contraction & 11 & 0.015103761 \\
15 & rno04360: Axon guidance & 10 & 0.048391286 \\
16 & rno04918: Thyroid hormone synthesis & 9 & 0.003507414 \\
17 & rno04520: Adherens junction & 9 & 0.00543844 \\
18 & rno04512: ECM-receptor interaction & 9 & 0.017206177 \\
19 & rno04722: Neurotrophin signaling pathway & 9 & 0.096478076 \\
20 & rno04961: Endocrine and other factor-regulated calcium & 7 & 0.007433825 \\
& reabsorption & & \\
\hline & & &
\end{tabular}


MS. Ultimately, bioinformatics analysis was performed to reveal their potential mechanism.

The Schwann cells in this study were isolated from the sciatic nerves of rats according to our previous methods, and by doing so, the purity of Schwann cells was more than 95\% [50]. Until now, there has been no advanced method to purify cultured Schwann cells to $100 \%$, and fibroblast contamination is difficult to avoid [51]. Despite the existence of the infinite cell line RSC96, which acts as an alternative for primary Schwann cells in some aspects [52], comparative proteomic analysis confirmed that this cell line exhibited different secreted protein expression profiles [53]. In this study, we purified Schwann cells to approximately $100 \%$ purity, which can give us reliable results.

The GO analysis of proteomics data revealed that the proteins in SCDEs were enriched in cellular processes, cellular processes involving biological regulation, which indicated that the contents of exosomes share close ties with microenvironment regulation. This regulatory characteristic is consistent with the supporting cell status for Schwann cells [54]. In the cellular component of GO analysis, the enrichment of cytoplasm and cytosol reflects the origin of exosomes. In addition, membrane-bound vesicles and plasma membranes are consistent with exosome features. For molecular function, protein binding is the most common characteristic, revealing that direct regulation of protein-protein interaction might be the main kind of regulation for SCDEs.

We used the KEGG pathway database to explore the enrichment of proteins and found that several signaling pathways were related to proteins in SCDEs. Some pathways reflect the basic biofunction of cells, such as the proteasome, glycolysis and regulation of the actin cytoskeleton, which proved that exosomes act as a suborgan of the host cells. We noticed that some proteins were enriched in the ribosome pathway, which is consistent with the fact that Schwann cells can transfer ribosomes to nearby axons and confirms that Schwann cells play an important role in supporting local protein synthesis in axons [55]. In the future, we will explore whether regeneration-related mRNAs exist in such exosomes.

Considering the potential therapeutic ability of CNS, we found that several enriched pathways are related to the CNS microenvironment, including the neurotrophin signaling pathway, PI3K-Akt signaling pathway and cAMP signaling pathway. In the neurotrophin signaling pathway, we found that Rho GTPases were detected, especially Rac1 and Cdc42. The Rho family of GTPases belongs to the Ras superfamily and plays an important role in neuronal development, neuronal survival and neurodegeneration [56]. In the CNS, Rac 1 and Cdc42 can promote neurite outgrowth and stimulate regeneration [57]. In contrast to neurons, astrocytes are always activated and form glial scars to inhibit axon regeneration [58]. The high expression of Rac1 can inhibit astrocyte outgrowth [59]. Meanwhile, Rac1 and Cdc42 can cause astrocyte apoptosis induced by neurotoxicity [60]. In addition, activation of Rac1 and Cdc42 can change microglia into the M2-like phenotype, which is beneficial in CNS regeneration [61]. Analogously, Rac 1/Cdc42 signaling can promote the migration of oligodendrocytes, the key cells in CNS for myelinization [62]. A recent study also proved that the activation of Rac1 can preserve blood-spinal cord barrier (BSCB) integrity and improve functional recovery after spinal cord injury through protection of endothelial cells [63].

\section{Conclusions}

The proteins in SCDEs can create a more permissive microenvironment related to each component in the CNS for regeneration. Our proteomics analysis may provide a novel therapeutic strategy for CNS injury.

Acknowledgements We thanked the support of the following funding: NSFC Program $(81330042,81620108018,81672171,81702147)$, Ministry of Science and Technology, China (2014DFR31210), Tianjin Science and Technology Committee, China (13RCGFSY19000, 14ZCZDSY00044).

\section{Compliance with Ethical Standards}

Competing interests No competing interests exist in the submission of this manuscript.

Conflict of interest All authors declare no conflict of interests and no disclosures relevant to the manuscript.

Ethical approval All authors have read the Journal's position on issues involved in ethical publication, and all authors have approved the final version of the manuscript.

Open Access This article is distributed under the terms of the Creative Commons Attribution 4.0 International License (http://creativeco mmons.org/licenses/by/4.0/), which permits unrestricted use, distribution, and reproduction in any medium, provided you give appropriate credit to the original author(s) and the source, provide a link to the Creative Commons license, and indicate if changes were made.

\section{References}

1. Ning GZ, Wu Q, Li YL, Feng SQ (2012) Epidemiology of traumatic spinal cord injury in Asia: a systematic review. J Spinal Cord Med 35:229-239. https://doi.org/10.1179/2045772312 y.0000000021

2. Rubiano AM, Carney N, Chesnut R, Puyana JC (2015) Global neurotrauma research challenges and opportunities. Nature 527:S193-S197. https://doi.org/10.1038/nature16035

3. O'Shea TM, Burda JE, Sofroniew MV (2017) Cell biology of spinal cord injury and repair. J Clin Invest 127:3259-3270. https ://doi.org/10.1172/jci90608 
4. Yiu G, He Z (2006) Glial inhibition of CNS axon regeneration. Nat Rev Neurosci 7:617-627. https://doi.org/10.1038/nrn1956

5. Assinck P, Duncan GJ, Hilton BJ, Plemel JR, Tetzlaff W (2017) Cell transplantation therapy for spinal cord injury. Nat Neurosci 20:637-647. https://doi.org/10.1038/nn.4541

6. Wiliams RR, Bunge MB (2012) Schwann cell transplantation: a repair strategy for spinal cord injury? Prog Brain Res 201:295312. https://doi.org/10.1016/b978-0-444-59544-7.00014-7

7. Zhou XH, Ning GZ, Feng SQ, Kong XH, Chen JT, Zheng YF, Ban DX, Liu T, Li H, Wang P (2012) Transplantation of autologous activated Schwann cells in the treatment of spinal cord injury: six cases, more than five years of follow-up. Cell Transpl 21(Suppl 1):S39

8. Anderson KD, Guest J, Dietrich WD, Bunge MB, Curiel R, Dididze M, Green BA, Khan A, Pearse DD, Saraf-Lavi E (2017) Safety of autologous human schwann cell transplantation in subacute thoracic spinal cord injury. J Neurotrauma 34(21):2950-2963

9. Feng S, Kong X, Guo S, Chen J, Pei W, Xinlong MA, Sun Z (2005) Treatment of spinal cord injury with Co-grafts of genetically modified schwann cells by NGF gene and fetal spinal cord cell suspension in the rat. Neurotox Res 7:169-177

10. Kanno H, Pressman Y, Moody A, Berg R, Muir EM, Rogers JH, Ozawa H, Itoi E, Pearse DD, Bunge MB (2014) Combination of engineered Schwann cell grafts to secrete neurotrophin and chondroitinase promotes axonal regeneration and locomotion after spinal cord injury. J Neurosci 34:1838-1855. https://doi.org/10.1523/ jneurosci.2661-13.2014

11. Masoumeh F, Farzaneh S, Abdolkhaleg D, Zahra Hassannejad P, Fatemeh P, Vafa RM (2011) Schwann cell apoptosis and p75(NTR) siRNA. Iran J Allergy Asthma Immunol 10:53-59

12. Ahmad I, Fernando A, Gurgel R, Clark JJ, Xu L, Hansen MR (2015) Merlin status regulates p75 NTR expression and apoptotic signaling in Schwann cells following nerve injury 3 . Neurobiol Dis $82: 114-122$

13. Grimpe B, Pressman Y, Bunge MB, Silver J (2005) The role of proteoglycans in Schwann cell/astrocyte interactions and in regeneration failure at PNS/CNS interfaces. Mol Cell Neurosci 28:18-29

14. Mousumi G, Tuesta LM, Rocio P, Samik P, Kiara M, Abderrahman EM, Urs R, Damien Daniel P (2012) Extensive cell migration, axon regeneration, and improved function with polysialic acid-modified Schwann cells after spinal cord injury. Glia 60:979-992

15. Théry C (2011) Exosomes: secreted vesicles and intercellular communications. F1000 Biol Rep 3:15

16. Mathivanan S, Ji H, Simpson RJ (2010) Exosomes: extracellular organelles important in intercellular communication. J Proteom 73:1907-1920

17. Mathivanan S, Lim JW, Tauro BJ, Ji H, Moritz RL, Simpson RJ (2010) Proteomics analysis of A33 immunoaffinity-purified exosomes released from the human colon tumor cell line LIM1215 reveals a tissue-specific protein signature. Mol Cell Proteom Mcp 9:197

18. María Alejandra LV, Frederic P, Court FA (2013) Schwann cellderived exosomes enhance axonal regeneration in the peripheral nervous system. Glia 61:1795-1806

19. Lopez-Verrilli MA, Court FA (2012) Transfer of vesicles from schwann cells to axons: a novel mechanism of communication in the peripheral nervous system. Frontiers Physiol 3:205

20. Mathias RA, Lim JW, Ji H, Simpson RJ (2009) Isolation of extracellular membranous vesicles for proteomic analysis. Methods Mol Biol 528:227-242. https://doi.org/10.1007/978-1-60327 $-310-7 \_16$

21. Allen GW, Liu JW, León M De (2000) Depletion of a fatty acidbinding protein impairs neurite outgrowth in PC12 cells. Brain Res Mol Brain Res 76:315-324
22. Cheng Y, Cawley NX, Loh YP (2014) Carboxypeptidase E (NF$\alpha 1)$ : a new trophic factor in neuro- protection. Neurosci Bull 30:692-696

23. King VR, Alovskaya A, Wei DYT, Brown RA, Priestley JV (2010) The use of injectable forms of fibrin and fibronectin to support axonal ingrowth after spinal cord injury. Biomaterials 31:4447-4456

24. Figueroa JD, Serrano-Illan M, Licero J, Cordero K, Miranda JD, De Leon M (2016) Fatty acid binding protein 5 modulates docosahexaenoic acid-induced recovery in rats undergoing spinal cord injury. J Neurotrauma 33:1436-1449. https://doi.org/10.1089/ neu.2015.4186

25. King VR, Phillips JB, Hunt-Grubbe H, Brown R, Priestley JV (2006) Characterization of non-neuronal elements within fibronectin mats implanted into the damaged adult rat spinal cord. Biomaterials 27:485-496

26. Koch JC, Solis GP, Bodrikov V, Michel U, Haralampieva D, Shypitsyna A, Tönges L, Bähr M, Lingor P, Stuermer CAO (2013) Upregulation of reggie-1/flotillin-2 promotes axon regeneration in the rat optic nerve in vivo and neurite growth in vitro. Neurobiol Dis $51: 168-176$

27. Stuermer CA (2011) Microdomain-forming proteins and the role of the reggies/flotillins during axon regeneration in zebrafish

28. Hong-Chao P, Jin-Fei L, Li-Ping M, Yan-Qin S, Melitta S (2013) Major vault protein promotes locomotor recovery and regeneration after spinal cord injury in adult zebrafish. Eur J Neurosci 37:203-211

29. Lu Z, Yan S, Tao W, Mei C, Zheng W, Hong Z, Qiang D (2014) Curcumin promotes neurite outgrowth via reggie-1/flotillin-2 in cortical neurons. Neurosci Lett 559:7-12

30. Morrison BM, Tsingalia A, Vidensky S, Lee Y, Jin L, Farah MH, Lengacher S, Magistretti PJ, Pellerin L, Rothstein JD (2015) Deficiency in monocarboxylate transporter 1 (MCT1) in mice delays regeneration of peripheral nerves following sciatic nerve crush. Exp Neurol 263:325-338. https://doi.org/10.1016/j.expne urol.2014.10.018

31. Yong Y, Melitta S (2013) Syntenin-a promotes spinal cord regeneration following injury in adult zebrafish. Eur J Neurosci 38:2280-2289

32. Zhang M, Ma Z, Qin H, Yao Z (2017) Monocarboxylate transporter 1 in the medial prefrontal cortex developmentally expresses in oligodendrocytes and associates with neuronal amounts. Mol Neurobiol 54:1-12

33. Makio T, Kenta Y, Atsushi T, Ikuo M, Atsu A, Valérie C, Fujio M (2013) Role of neuropilin-2 in the ipsilateral growth of midbrain dopaminergic axons. Eur J Neurosci 37:1573-1583

34. Murthy SRK, Thouennon E, Li W-S, Cheng Y, Bhupatkar J, Cawley NX, Lane M, Merchenthaler I, Loh YP (2013) Carboxypeptidase $\mathrm{E}$ protects hippocampal neurons during stress in male mice by up-regulating prosurvival BCL2 protein expression. Endocrinology 154:3284-3293

35. Botia B, Seyer D, Ravni A, Bénard M, Falluel-Morel A, Cosette P, Jouenne T, Fournier A, Vaudry H, Gonzalez BJ (2008) Peroxiredoxin 2 is involved in the neuroprotective effects of PACAP in cultured cerebellar granule neurons. J Mol Neurosci 36:61-72

36. Zhang S, Wu D, Wang J, Wang Y, Wang G, Yang M (2013) Stress protein expression in early phase spinal cord ischemia/reperfusion injury. Neural Regen Res 8:2225-2235

37. Claudio H, Milene RC, Sébastien WL, Sonia C, Elisabeth VK, Kinsey M, Joaquín C, Claudio S (2005) The disulfide isomerase Grp58 is a protective factor against prion neurotoxicity. J Neurosci 25:2793-2802

38. Hetz CA, Claudio S (2006) Stressing out the ER: a role of the unfolded protein response in prion-related disorders. Curr Mol Med 6:37-43 
39. Bracchi-Ricard V, Lambertsen KL, Ricard J, Nathanson L, Karmally S, Johnstone J, Ellman DG, Frydel B, Mctigue DM, Bethea JR (2013) Inhibition of astroglial NF-kappaB enhances oligodendrogenesis following spinal cord injury. J Neuroinflamm 10:869

40. Gan Y, Ji X, Hu X, Luo Y, Zhang L, Li P, Liu X, Yan F, Vosler P, Gao Y, Stetler RA, Chen J (2012) Transgenic overexpression of peroxiredoxin-2 attenuates ischemic neuronal injury via suppression of a redox-sensitive pro-death signaling pathway. Antioxid Redox Signal 17:719-732. https://doi.org/10.1089/ ars.2011.4298

41. Hua H, Yayi X, Shuanke W, Bin Z, Zhengyi S, Lingwei Y (2011) Synergistic effects of galectin-1 and reactive astrocytes on functional recovery after contusive spinal cord injury. Arch Orthop Trauma Surg 131:829-839

42. Blackmore M, Letourneau PC (2006) L1, beta1 integrin, and cadherins mediate axonal regeneration in the embryonic spinal cord. J Neurobiol 66:1564-1583. https://doi.org/10.1002/neu.20311

43. Parri M, Chiarugi P (2010) Rac and Rho GTPases in cancer cell motility control. Cell Commun Signal 8:23. https://doi. org/10.1186/1478-811x-8-23

44. Lopez-Leal R, Alvarez J, Court FA (2016) Origin of axonal proteins: Is the axon-schwann cell unit a functional syncytium? Cytoskeleton (Hoboken) 73:629-639. https://doi.org/10.1002/ cm.21319

45. Lopez-Leal R, Court FA (2016) Schwann cell exosomes mediate neuron-glia communication and enhance axonal regeneration. Cell Mol Neurobiol 36:429-436

46. Seon-Hee K, Lechman ER, Nicole B, Rajasree M, Annahita K, Joan N, Zhibao M, Watkins SC, Andrea G, Robbins PD (2005) Exosomes derived from IL-10-treated dendritic cells can suppress inflammation and collagen-induced arthritis. J Immunol 174:6440

47. Seon Hee K, Bianco NR, Shufesky WJ, Morelli AE, Robbins PD (2007) MHC class II + exosomes in plasma suppress inflammation in an antigen-specific and Fas ligand/Fas-dependent manner. J Immunol 179:2235-2241

48. Teng H, Hu M, Yuan LX, Liu Y, Guo X, Zhang WJ, Jia RZ (2012) Suppression of inflammation by tumor-derived exosomes: a kind of natural liposome packaged with multifunctional proteins. J Liposome Res 22:346-352

49. Liu GJ, Werry EL, Bennett MR (2005) Secretion of ATP from Schwann cells in response to uridine triphosphate. Eur J Neurosci 21:151-160. https://doi.org/10.1111/j.1460-9568.2004.03831.x

50. De-Xiang B, Guang-Zhi N, Shi-Qing F, Ying W, Xian-Hu Z, Yang L, Jia-Tong C (2011) Combination of activated Schwann cells with bone mesenchymal stem cells: the best cell strategy for repair after spinal cord injury in rats. Regen Med 6:707-720

51. Kaewkhaw R, Scutt AM, Haycock JW (2012) Integrated culture and purification of rat Schwann cells from freshly isolated adult tissue. Nat Protoc 7:1996-2004. https://doi.org/10.1038/nprot .2012 .118

52. Chang YM, Chang HH, Tsai CC, Lin HJ, Ho TJ, Ye CX, Chiu PL, Chen YS, Chen RJ, Huang CY (2017) Alpinia oxyphylla
Miq. fruit extract activates IGFR-PI3K/Akt signaling to induce Schwann cell proliferation and sciatic nerve regeneration. Bmc Complement Altern Med 17:184

53. Yuhua J, Mi S, Xin W, Shuqiang Z, Shu Y, Gang C, Xiaosong G, Fei D (2012) Comparative proteomic analysis of primary schwann cells and a spontaneously immortalized schwann cell line RSC 96: a comprehensive overview with a focus on cell adhesion and migration related proteins. J Proteome Res 11:3186-3198

54. Goldman SA, Maiken N, Windrem MS (2012) Glial progenitor cell-based treatment and modeling of neurological disease. Science 338:491-495

55. Court FA, Hendriks WTJ, Macgillavry HD, Jaime A, Jan VM (2008) Schwann cell to axon transfer of ribosomes: toward a novel understanding of the role of glia in the nervous system. J Neurosci 28:11024-11029

56. Stankiewicz TR, Linseman DA (2014) Rho family GTPases: key players in neuronal development, neuronal survival, and neurodegeneration. Frontiers Cell Neurosci 8:314

57. Matsukawa T, Morita K, Omizu S, Kato S, Koriyama Y (2018) Mechanisms of RhoA inactivation and CDC42 and Rac1 activation during zebrafish optic nerve regeneration. Neurochem Int 112:71-80. https://doi.org/10.1016/j.neuint.2017.11.004

58. Renault-Mihara F, Mukaino M, Shinozaki M, Kumamaru H, Kawase S, Baudoux M, Ishibashi T, Kawabata S, Nishiyama Y, Sugai K (2017) Regulation of RhoA by STAT3 coordinates glial scar formation. J Cell Biol 216:2533

59. Zeug A, Müller FE, Anders S, Herde MK, Minge D, Ponimaskin E, Henneberger C (2018) Control of astrocyte morphology by Rho GTPases. Brain Res Bull 136:44-53

60. An Y, Liu T, Liu X, Zhao L, Wang J (2016) Rac1 and Cdc42 play important roles in arsenic neurotoxicity in primary cultured rat cerebellar astrocytes. Biol Trace Elem Res 170:173-182. https:// doi.org/10.1007/s12011-015-0456-7

61. Neubrand VE, Pedreno M, Caro M, Forte-Lago I, Delgado M, Gonzalez-Rey E (2014) Mesenchymal stem cells induce the ramification of microglia via the small RhoGTPases Cdc42 and Rac1. Glia 62:1932-1942. https://doi.org/10.1002/glia.22714

62. Yingying D, Yun G, Youjuan H, Yingjie W, Yan L, Mei L, Fei D, Xiaosong G, Yongjun W (2013) HMGB1 protein does not mediate the inflammatory response in spontaneous spinal cord regeneration: a hint for CNS regeneration. J Biol Chem 288:18204-18218

63. Zheng B, Ye L, Zhou Y, Zhu S, Wang Q, Shi H, Chen D, Wei X, Wang Z, Li X (2016) Epidermal growth factor attenuates bloodspinal cord barrier disruption via PI3K/Akt/Rac1 pathway after acute spinal cord injury. J Cell Mol Med 20:1062-1075

Publisher's Note Springer Nature remains neutral with regard to jurisdictional claims in published maps and institutional affiliations. 